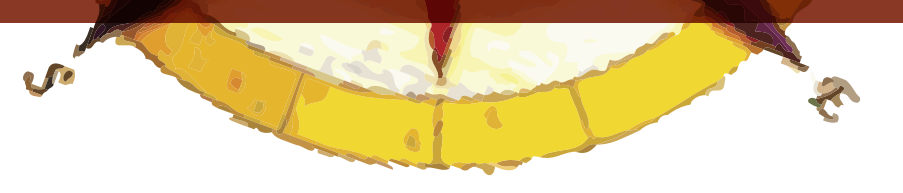

\title{
A FORMAÇÃO DE PROFESSORES E A PRÁTICA DOCENTE EM GEOGRAFIA NO CONTEXTO DA EDUCAÇÃO DE JOVENS E ADULTOS MEDIADOS PELA CARTOGRAFIA
}

\author{
Caroline Geraldini Ferreira Rezende ${ }^{1}$
}

\section{RESUMO}

Este texto é resultado de uma pesquisa realizada durante o Mestrado em Geografia, que analisou a ação mediadora da Cartografia no processo de ensino-aprendizagem da Educação de Jovens e Adultos (EJA) possibilitando, consequentemente, a formação continuada de professores de Geografia dessa modalidade de ensino. A pesquisa foi desenvolvida junto a professores da Terceira Etapa (Ensino Médio) em uma unidade da Rede Estadual de Educação, que oferece EJA, no município de Goiânia, Estado de Goiás/Brasil. A partir de uma metodologia qualitativa através da pesquisa participante, utilizou-se técnicas de investigação que primaram pela relação entre a teoria e a prática, buscando uma interação dialética na perspectiva da práxis. Analisou-se o papel da Geografia Escolar e da Cartografia na formação dos alunos da modalidade EJA e na formação continuada do professor, uma vez que a construção do conhecimento geográfico e cartográfico pode contribuir na melhoria do processo de ensino-aprendizagem dessa modalidade de ensino, possibilitando uma melhor interpretação da realidade.

Palavras-chave: Ensino de jovens e adultos - Formação continuada de professores - Cartografia escolar

\section{RESUMEN}

Este texto es el resultado de una investigación realizada durante la Maestría en Geografía, que examinó la acción mediadora de la Cartografía en la educación de enseñanza-aprendizaje para jóvenes y adultos (EJA), permitiendo así la formación continua de los profesores de Geografía esta modalidad de educación. La investigación fue realizada con profesores de la Tercera Etapa en una unidad de la Red de Educación del Estado en Goiânia, Goiás/Brasil, lo que ofrece la educación

1 Professora da Rede Estadual de Ensino do Estado de Goiás 
de adultos. A partir de una metodología cualitativa a través de la encuesta de los participantes, se utilizaron técnicas de investigación por la relación entre la teoría y la práctica, la búsqueda de una interacción dialéctica desde la perspectiva de la praxis . Se analizó el papel de la Escuela de Geografía y Cartografía en la formación de modo EJA estudiantes y continuando la formación del profesorado, ya que la construcción del conocimiento geográfico y cartográfico puede contribuir a mejorar el proceso de enseñanza - aprendizaje de este tipo de educación, permitiendo una mejor interpretación de la realidad.

Palabras clave: Educación para jóvenes y adultos - Formación continua para los profesores - Cartografía Escolar

\begin{abstract}
This text is the result of a survey conducted during the Masters in Geography, which examined the mediating action of Cartography in the teaching-learning Education for Youths and Adults (EJA) process, thus enabling the continuing education of teachers of this modality of Geography education. The research was conducted with teachers from the Third Stage (High School) in a unit of the State Education Network, which offers adult education, in Goiânia, state of Goiás/Brazil. From a qualitative methodology through participant survey, we used research techniques that were conspicuous by the relationship between theory and practice, seeking a dialectical interaction from the perspective of praxis. We analyzed the role of the School of Geography and Cartography in the training of students EJA mode and continuing teacher education, since the construction of the geographic and cartographic knowledge can contribute in improving the teaching-learning process of this type of education, enabling better interpretation of reality.
\end{abstract}

Keywords

Teaching young people and adults - Continuing teacher education - School Cartography

\title{
INTRODUÇÃO
}

A formação inicial do licenciado em Geografia atende as necessidades do aluno de ensino regular e, de certa forma, esquece o aluno da Educação de Jovens e Adultos (EJA). Ela enfatiza um público que requer tratamento diferenciado e, muitas vezes, os profissionais da educação que atuam nesta modalidade não compreendem ou não são preparados para enfrentar esta realidade.

Uma das funções permanentes da EJA é propiciar a todos a atualização de conhecimentos por toda a vida, que segundo o parecer do Conselho Nacional de Educação (CNE) 11/2000 pode se chamar de qualificadora, tendo como base o caráter de atualização e desenvolvimento, proporcionando a criação de uma sociedade educada para o universalismo, a solidariedade, a igualdade e a diversidade. Assim se torna possível ao ser humano se qualificar, requalificar e descobrir novos campos de atuação como realização de si.

Mediante esta situação levantamos o questionamento: como auxiliar o professor de Geografia de EJA, através da Cartografia, na construção dos conhecimentos geográficos para o processo de 
ensino-aprendizagem? Nessa perspectiva, a proposta da pesquisa foi discutir a capacidade mediadora da Cartografia na construção do conhecimento geográfico, bem como na formação continuada dos professores de Geografia nessa modalidade de ensino.

A pesquisa foi desenvolvida, junto aos professores da Terceira Etapa (Ensino Médio) em uma unidade da Rede Estadual de Educação que oferece EJA no município de Goiânia/GO, ao longo dos anos de 2012 e 2013. Ao contrário de uma postura de pesquisadores observadores neutros, objetivos e descritivos, optamos pela metodologia da pesquisa participante (Demo, 2008). Para o desenvolvimento da pesquisa foram utilizadas técnicas qualitativas de investigação como a observação participante em uma sala de aula do $1^{\circ}$ semestre da Terceira Etapa de EJA, entrevistas livres e semiestuturadas com os professores envolvidos na pesquisa, atividades para os alunos e análise dessas atividades. Todos estes procedimentos primaram pela relação entre a teoria e a prática, buscando uma interação dialética, trabalhando sempre na perspectiva da práxis, pois acreditamos que a construção do conhecimento geográfico e cartográfico contribui na melhoria do processo de ensinoaprendizagem de alunos de EJA, possibilitando uma melhor interpretação da realidade.

O envolvimento dos professores de Geografia da EJA na pesquisa foi de fundamental importância na perspectiva de diversificar os recursos didáticos para propiciar um efetivo processo de ensinoaprendizagem mediado pela Cartografia, contribuindo também para a formação continuada deste profissional.

\section{CARACTERÍSTICAS DA EJA NO ESTADO DE GOIÁS}

De acordo com pesquisas realizadas pela Secretaria de Educação do Estado de Goiás (SEDUC), em 38 Subsecretarias Regionais de Educação e unidades escolares buscou-se averiguar a realidade dos professores que trabalham com EJA no Estado de Goiás. Esse estudo indicou que a grande maioria dos docentes são graduados e trabalham nos três turnos, com uma sobrecarga de 60 horas semanais, e não são professores exclusivos dessa modalidade. Alguns completam a carga horária em outra unidade escolar, dificultando sua prática docente e a especialização nesta modalidade, não disponibilizando de tempo para participar de todas as atividades desenvolvidas na unidade escolar, como grupo de estudo, trabalho coletivo, socialização de projetos interdisciplinares, debates e outros.

Este quadro nos mostra a grande dificuldade que os professores de EJA enfrentam diante da intenção de aprimorar sua qualificação, no que diz respeito à melhora do processo de ensino-aprendizagem específica a esta modalidade de ensino. A realidade enfrentada é de que estes profissionais, mesmo que queiram se dedicar exclusivamente a esta modalidade, são impedidos por não conseguirem completar sua carga horária e, também, por não encontrarem pós-graduações específicas.

Já o quadro inverso, que não podemos deixar de mencionar, se relaciona ao fato de que muitos professores que preferem lecionar no ensino regular acabam completando sua carga horária com a EJA, não tendo como prioridade o trabalho com esta modalidade de ensino. Muitos não gostam ou não se sentem aptos a trabalhar com jovens e adultos, e acabam por lecionar em turmas de EJA por necessidade financeira.

O processo de avaliação dos alunos desta modalidade deve considerar, cotidianamente, a efetiva presença e a participação do estudante nas atividades escolares, sua comunicação com os colegas, 
com os professores e com os demais agentes educativos, sua sociabilidade, sua capacidade de tomar iniciativa, de criar e de apropriar-se dos conteúdos ministrados, visando à aquisição de conhecimentos, o desenvolvimento das habilidades de ler, escrever e interpretar, de atitudes e de valores indispensáveis ao pleno exercício da cidadania.

Nesta busca pela compreensão do quadro geral que envolve professores e alunos da EJA, damos uma atenção especial às características dos alunos da EJA, buscando subsídios na recente pesquisa realizada por Ribeiro (2011), a qual nos mostrou as especificidades desta modalidade de ensino e as de seus respectivos estudantes, uma vez que esta autora trabalhou com a "Formação cidadã, juventude e trabalho: A Geografia na Educação de Jovens e Adultos (EJA)". Esse estudo preocupou-se com a descrição das escolas-campo e o perfil dos jovens estudantes da EJA do município de Goiânia/Goiás e da Região Metropolitana de Goiânia (RMG).

No ensino público estadual de Goiânia e da RMG existe uma grande quantidade de jovens entre 19 e 22 anos, que estudam, principalmente, no período matutino, sendo que no período noturno encontra-se a maior quantidade de alunos com idade superior a 23 anos, os quais, geralmente, optam por essa modalidade de ensino devido ao trabalho e por já constituírem família.

Ribeiro (2011, p.48) afirma que a conciliação da atividade profissional e dos estudos trazem preocupações aos jovens, uma vez que a dupla jornada exige esforços durante o dia e à noite, para que possam atender às expectativas geradas nos ambientes escolares e de trabalho. Juntamente a este contexto levantam-se outros anseios como o de ter tempo para o descanso, para o lazer, para o namoro, para os amigos e para a família.

De acordo com a SEDUC (GOIÁS, 2010), em seu documento sobre as Diretrizes da Educação de Jovens e Adultos do Estado de Goiás, a partir das Matrizes de Expectativas de Aprendizagem, os educadores puderam escolher os livros didáticos, porém, infelizmente as opções de escolha foram somente do ensino regular devido a falta de opções de livros didáticos adequados a EJA. Os livros foram distribuídos a partir de 2011 pelo Governo Federal, sendo entregues nas escolas públicas que oferecem EJA. A decisão consta da Resolução n ${ }^{\circ} 51$ do Fundo Nacional de Desenvolvimento da Educação (FNDE), cuja norma cria o Programa Nacional do Livro Didático para Educação de Jovens e Adultos (PNLD-EJA). Pode-se notar que até o ano de 2010, ocorria uma inexistência de material didático para a modalidade EJA referente à Terceira Etapa (Ensino Médio), o que nos faz refletir como a exclusão vem acompanhando esta modalidade e como isto vem se perpetuando desde os primeiros anos de colonização no Brasil até o século XXI. Contudo, a partir do ano de 2011, professores e alunos receberam livros didáticos como apoio ao processo de ensino-aprendizagem, mesmo que estes fossem voltados para o ensino regular e não para a EJA.

Outro problema enfrentado nesta modalidade de ensino trata da constante ausência dos alunos por dias e até mesmo por semanas letivas, por motivos variados como: alteração temporária de horário de trabalho, cursos obrigatórios realizados no trabalho, doença na família, acompanhamento de filhos e outros motivos. Diante de todos estes tipos de imprevistos, a escola busca ser tolerante e considerar as adversidades vividas pelos estudantes para que estes não percam o período escolar, uma vez que o curso de EJA na rede estadual de ensino configura-se como um curso presencial e as faltas podem levar os alunos à reprovação. 
As observações realizadas por Ribeiro (2011) mostraram uma grande influência da mídia televisiva, uma vez que os professores desta modalidade tendem a contextualizar o ensino, buscando relacionar os conteúdos com a realidade por meio de exemplos e perguntas sobre o cotidiano. Outra característica marcante da EJA é que a maioria de seus alunos trabalha, e trata isso com orgulho, citando muitas vezes durante as aulas, exemplos vividos no cotidiano de seus trabalhos. Outra característica interessante é que esses alunos procuram participar mais das atividades e se preocupam mais com a resolução de atividades propostas. É importante ressaltar que as leituras, diálogos e exercícios realizados têm sempre por objetivo a apropriação do conhecimento pelo estudante.

Pudemos observar que toda esta temática leva o grupo, professores e alunos, a terem uma interação. As unidades de ensino de EJA buscam compreender as realidades vividas por seus alunos e suas demandas, preparando-os não só para o mercado de trabalho, mas também para enfrentarem os desafios sociedade contemporânea. Os professores buscam fazer com que os estudantes se apropriem dos conhecimentos científicos, relacionando-os com os saberes adquiridos ao longo da vida proporcionando um pensamento crítico e responsável.

Uma das preocupações levantadas pela VI Conferência Internacional de Educação de Adultos (CONFINTEA) é de que a educação inclusiva é preponderante para a realização do desenvolvimento humano, social e econômico. Para que isso seja possível é fundamental que não haja exclusão decorrente de idade, gênero, etnia, condição de imigrante, língua, religião, deficiência, ruralidade, identidade ou orientação sexual, pobreza, deslocamento ou encarceramento. Assim, a EJA deve procurar efetuar medidas para aumentar o acesso daqueles que por algum motivo não puderam realizar seus estudos nas idades compatíveis, fazendo valer a educação como um direito desfrutado por todos

\section{A FORMAÇÃO DE PROFESSORES NO CONTEXTO DA EJA}

É de fundamental importância realizar uma abordagem sobre a formação inicial e continuada de professores da EJA, uma vez que a sociedade está a exigir profissionais capacitados e preparados para lidar com novas situações e novas tecnologias. Para tanto se faz preponderante compreender como a universidade vem procurando efetivar a aproximação entre teoria e prática, pois este é o principal viés para que as necessidades do ensino regular e da educação de jovens e adultos sejam atendidas.

Para atingir um alto nível de qualidade no processo ensino-aprendizagem o professor precisa buscar, constantemente, atualizar-se renovando seus conhecimentos. Para isso, a formação continuada passa a ser o principal aliado deste profissional. A forma com que as universidades tratam este tema poderá gerar uma educação mais sólida, pois o professor se torna um agente de sua própria formação através da reflexão de seus métodos e sua prática.

\section{Contexto geral sobre a formação de professores de EJA}

O contexto atual da formação de professores para EJA toma, como referência, a reconceituação da EJA a partir da Lei de Diretrizes e Bases da Educação Nacional (LDB 9394/96) buscando compreender o campo da formação inicial e continuada de professores para a EJA. 
Machado (2008) evidencia vários conceitos que se cristalizaram ao longo dos anos a respeito da EJA no Brasil, e uma delas é a ideia de que o aluno jovem e adulto que retorna à escola tem pressa, precisando assim de "um curso rápido e fácil" com o objetivo de receber certificação. Sendo assim, os cursos poderiam ser oferecidos sem muita exigência quanto ao processo de avaliação dos alunos jovens e adultos. Outra ideia seria a de que os alunos não teriam interesse no aprendizado, por isso não seria necessária a preocupação com a qualidade dessa modalidade de ensino.

A autora destaca que os fatos relatados anteriormente não seriam em sua totalidade falsos, pois é verdadeiro que quando o jovem ou adulto retorna aos estudos após vários anos tem um grande interesse de recuperar o "tempo perdido", principalmente para de ingressar ou mesmo permanecer no mercado de trabalho. Porém, estes fatos, segundo Machado (2008, p. 162), não justificaria uma escolarização aligeirada, "já que a educação básica precisa primar pelo princípio da igualdade de direito de acesso ao conhecimento produzido pela humanidade - e não pautar-se pelas exigências de mercado".

Neste contexto, a autora segue dizendo que é preciso compreender como os professores são preparados para atuar nessa modalidade de ensino, visto que se trata de um público diferenciado do público do ensino regular.

Esta preocupação também está presente na Resolução CNE/CEB n ${ }^{\circ} 11 / 2000$, que vem a ser um instrumento que orienta a lei. Daí a importância de nós, educadores, compreendermos a necessidade de conhecer esses instrumentos legais e de lutarmos para que de fato eles se materializem em nossa ação pedagógica. Certamente, não é difícil encontrar, depois de quatorze anos dessa resolução, muitos professores de EJA e muitos formadores de professores que ainda não sabem e não vêem, na prática, acontecer o que está previsto nesta resolução:

Art. 17 - A formação inicial e continuada de profissionais para a Educação de Jovens e Adultos terá como referência as diretrizes curriculares nacionais para o ensino fundamental e para o ensino médio e as diretrizes curriculares nacionais para a formação de professores, apoiada em:

I - ambiente institucional com organização adequada à proposta pedagógica;

II - investigação dos problemas desta modalidade de educação, buscando oferecer soluções teoricamente fundamentadas e socialmente contextuadas;

III - desenvolvimento de práticas educativas que correlacionem teoria e prática;

IV - utilização de métodos e técnicas que contemplem códigos e linguagens apropriados às situações específicas de aprendizagem. (Brasil, 2000b).

Quanto à formação de professores para a EJA, podemos dizer que anteriormente à LDB/96 o formato padrão não previa formação específica para o atendimento os alunos jovens e adultos. A formação específica para EJA teve início no final da década de 1980, quando as faculdades de Educação realizaram amplo debate sobre a atuação do pedagogo e sua habilitação profissional. Assim, surgiram alguns cursos de pedagogia distribuídos em três das cinco regiões do país, com ênfase ou habilitação em EJA, o que na realidade ainda era insuficiente. Essa realidade pouco mudou ao longo dos anos, pois vem se confirmando a quase total ausência de formação específica dos cursos de licenciatura do país que visam à atuação em EJA. 
Os cursos de disciplinas específicas como História, Letras, Geografia, Matemática, Química, Educação Física e todas as outras licenciaturas, que habilitaram professores até o final dos anos 1990, de acordo com Machado (2008), não possibilitaram aos futuros professores aprender, nas disciplinas pedagógicas e no estágio, sobre os desafios da atuação com os alunos jovens e adultos que retornam ao processo de escolarização, anos após estarem afastados da escola.

A maioria dos cursos de formação de professores nos prepara para atuar com o aluno ideal - por que não dizer irreal. Aprendemos os conteúdos de nossas áreas, conhecemos algumas ferramentas pedagógicas e metodológicas, mas estamos longe de pensar a realidade concreta da escola na qual iremos atuar, ao assumir um contrato temporário ou, mesmo, ao passar num concurso para cargos efetivos nas redes públicas de ensino. É a primeira questão a ser enfrentada pela formação de professores da EJA: há que se repensar os currículos dos cursos de licenciatura, para que a formação inicial trate dessa modalidade de ensino. (Machado, 2008, p. 166)

Machado (2008) tece, de forma clara e objetiva, que hoje o maior desafio não seria apenas o de se pensar nos professores que estão ingressando na formação inicial, na graduação, pois além deste aspecto, existe um número significativo de docentes já graduados, atuando na EJA, nas redes públicas de ensino. Para estes seriam necessárias estratégias de formação continuada, seja no nível de aperfeiçoamento, seja na perspectiva da pós-graduação latu sensu e stricto sensu.

Além disso, Machado (2008) ainda nos mostra que na última década ocorreram esforços em torno da reconfiguração do campo da EJA e estes trouxeram mudanças no campo da formação de professores. A autora destaca dois movimentos importantes. O primeiro movimento é mais ligado aos órgãos oficiais de governo, com a presença importante do órgão normativo nacional em educação: o CNE, que, através da Câmara de Educação Básica (CEB) fixou, no ano de 2000, as Diretrizes Curriculares para a EJA e, outro, que advém da sociedade civil organizada em defesa da EJA, com destaque para a participação dos fóruns de EJA e do Grupo de Trabalho de Educação de Jovens e Adultos, da Associação Nacional de Pós-Graduação e Pesquisa em Educação (Anped).

O segundo movimento destacado por Machado (2008) é liderado pela sociedade civil, composto por representantes dos sistemas públicos de ensino diretamente designados pelo Governo Federal, estaduais ou municipais. Embora algumas ações contem com a participação do poder público, os fóruns são instâncias de mobilização e debate em torno da política pública de educação para jovens e adultos e estão presentes em todos os estados da federação e no Distrito Federal. São compostos de representantes de vários segmentos, que atuam direta ou indiretamente na EJA: universidades, movimentos populares, redes públicas de ensino, conselhos municipais e estaduais de educação, sindicatos, organizações não governamentais, empresas, educandos e educadores2.

Os fóruns realizam anualmente o Encontro Nacional de Educação de Jovens e Adultos (Eneja), que vem ocorrendo desde 1999. Dos relatórios dos ENEJA, vale destacar, algumas das preocupações e proposições quanto à formação de professores que permanecem, até os dias atuais:

- A criação de uma rede de formação e pesquisa deverá ser concebida com a contribuição do segmento universidades dos Fóruns de EJA, coordenação da Anped e segmento de educadores populares e professores da rede pública;

2 A forma de articulação no estado e nos regionais depende da dinâmica de cada fórum, como se pode aferir no sítio www.forumeja.org.br. 
- Garantir investimentos da esfera pública, em formação inicial e continuada específica para EJA;

- O educador de EJA deve ser reconhecido como pesquisador de sua práxis pedagógica, sendo este o princípio orientador da formação na graduação e pós-graduação;

- Garantir o acesso dos educadores da EJA e educadores populares nas universidades, gratuitamente em cursos de licenciatura;

- Que o governo federal crie mecanismos que viabilizem o processo de formação inicial e continuada, por meio de parcerias entre as redes públicas e as instituições de educação superior, promovendo cursos de licenciatura para educadores da EJA e educadores populares (Eneja, 2007).

Mediante todas estas proposições, acreditamos que, se de fato concretizadas, teremos uma melhora significativa no processo de ensino-aprendizagem para alunos da modalidade de ensino de EJA. Para tanto, nos cabe analisar também a contribuição das áreas específicas no processo de formação de professores dessa modalidade de ensino. Nesse caso, temos como foco o ensino de Geografia, área que participa do currículo escolar da Educação Básica no Brasil, tanto regular quando EJA, e tem grande potencialidade para trabalhar com temas e conteúdos pertinentes a construção de saberes dos estudantes jovens e adultos.

\section{A FORMAÇÃO DO PROFESSOR DE GEOGRAFIA PARA EJA}

Para proporcionar uma reflexão sobre quais seriam os objetivos do ensino de Geografia para a EJA, elaboramos um quadro (Quadro 1) trazendo as propostas levantadas por Antunes (2012) como auxílio aos professores desta modalidade, para que estes proporcionem a seus alunos aspectos essenciais:

Quadro 1 - conhecimentos geográficos para alunos de eja e conhecimentos essenciais aos professores de eja

\begin{tabular}{|c|c|}
\hline $\begin{array}{c}\text { CONHECIMENTOS GEOGRÁFICOS PARA } \\
\text { ALUNOS DE EJA }\end{array}$ & $\begin{array}{c}\text { CONHECIMENTOS ESSENCIAIS AOS } \\
\text { PROFESSORES DE EJA } \\
\end{array}$ \\
\hline $\begin{array}{l}\text { Conhecer, ainda que de forma "enxuta", } \\
\text { a diversidade do mundo em que vivemos, } \\
\text { compreendendo como paisagens, lugares e } \\
\text { territórios se transformam. }\end{array}$ & $\begin{array}{l}\text { Organizar e dirigir situações de aprendizagem: } \\
\text { Selecionar os conteúdos que efetivamente devem } \\
\text { ser trabalhados com alunos adultos. Ver no erro do } \\
\text { aluno a oportunidade de ajuda. }\end{array}$ \\
\hline
\end{tabular}




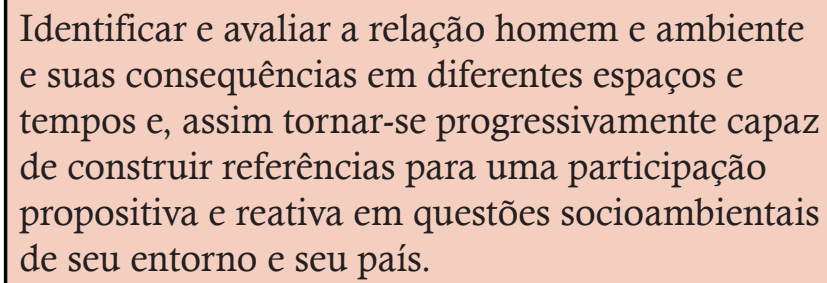

Identificar e avaliar a relação homem e ambiente e suas consequências em diferentes espaços e tempos e, assim tornar-se progressivamente capaz de construir referências para uma participação propositiva e reativa em questões socioambientais de seu entorno e seu país.

Conhecer a natureza em suas múltiplas relações, de modo a identificar de forma crítica o papel humano na construção e na alteração do lugar.

Compreender a espacialidade e a temporalidade dos fenômenos e fatos geográficos, suas interações e suas dinâmicas.

Perceber que a desigualdade nas condições de vida e oportunidades de trabalho, os direitos políticos, os avanços tecnológicos e as transformações socioculturais são conquistas ainda não democratizada por todos os habitantes do entorno, do país e do planeta.

Aprender a se utilizar de procedimentos críticos de análise e pesquisa inerentes à Geografia para compreender a paisagem, o território e o lugar, seus processos de construção, suas relações, problemas e contradições.

Saber fazer uso da linguagem cartográfica e da interpretação de gráficos e infográficos para colher interpretações e representar a espacialidade dos fenômenos geográficos.

Aprender a respeitar e assim valorizar o patrimônio sociocultural com sua sociodiversidade, reconhecendo-os como direito dos povos e dos indivíduos e, desse modo, fortalecer o sentimento de civismo, liberdade e de democracia.
Administrar processos de progressão das aprendizagens:

Administrar situações-problema ajudadas ao nível da classe, assumir visão longitudinal sobre os objetivos do ensino, fazer um balanço permanente das competências trabalhadas para verificar sua progressão.

Perceber e desenvolver dispositivos de diferenciação.

Assumir que toda classe é heterogênea e saber administrar essas diferenças e desenvolver esquema de cooperação entre alunos.

Envolver geográfica do mundo em que vivem:

Estimular-se pelo que ensina suscitando no aluno o desejo de aprender, mostrar a relação entre o que se aprende e o que se sabe, organizar e saber ouvir um "conselho" formado por seus alunos para ouvi-los.

Ensinar os alunos a organizar, administrar e trabalhar em grupos:

Assumir estratégias de trabalho em grupo voltadas à cooperação, ensinar os alunos a compartilhar aprendizagens e saberes, desenvolvendo projetos pedagógicos cooperativos.

Dominar e fazer uso de novas tecnologias:

Aprender a utilizar novas tecnologias sem se deixar dominar por essas rotinas. Usar de maneira significativa a internet e outros recursos eletrônicos.

Saber identificar e superar os conflitos éticos da profissão de professor de alunos jovens e adultos:

Lutar em todas as oportunidades contra todas as formas de discriminação, assumir uma relação efetivamente cooperativa e interdisciplinar com a equipe de colegas, estudar e aprender sempre.

Construir práticas de cidadania que promovam o diálogo entre os diversos sujeitos que compõe a sociedade, a partir do reconhecimento suas especificidades, histórias, contextos, entre outros.

Organização: Rezende, 2014.

Fonte: Adaptado de ANTUNES, 2012, p. 36, 64 e 65. 
A partir desse quadro podemos observar a importância do professor de EJA em buscar sempre os conhecimentos já adquiridos pelos alunos ao longo de suas práticas cotidianas, que possibilitam um maior diálogo entre os saberes sistematizados com a vivência e experiência desses sujeitos. Assim, o professor poderá proporcionar saberes que possam valer para o mundo das relações, do viver e conviver.

Contudo, ao fazer o uso da significação o ensino de Geografia deve ser pensado de maneira a valorizar os conhecimentos experienciais dos alunos da EJA, pois pensando no perfil desses alunos, seus saberes e experiências, é necessário desenvolver uma Geografia voltada para auxiliar o indivíduo na compreensão do mundo que o cerca.

Resende $(1986$, p. 20, 21) defende que o espaço real dos alunos, "aquele espaço cuja lógica eles experimentaram na própria carne, espaço que faz parte de suas histórias, das múltiplas atividades que 'enchem' suas vidas", deve ser considerado no processo de ensino-aprendizagem da EJA. Ou seja, tudo aquilo que os alunos trazem consigo, suas experiências, a absorção da espacialidade que o circunda, cabendo ao professor fazer uso deste saber e ensinando-lhes o espaço geográfico. Isso possibilita através das concepções geográficas a ampliação de seus conhecimentos, impulsionandoos a serem cidadãos mais críticos e reflexivos. Cabe aos professores de EJA considerar o saber geográfico do aluno, mesmo que este conhecimento seja considerado prévio, para que a ação docente participativa possa aperfeiçoar os saberes do cotidiano de suas vidas.

Nesse sentido objetivamos, através da mediação Cartográfica, proporcionar ao professor de Geografia da EJA um modo de intervenção pedagógica que viesse a ser significativo para o desenvolvimento dos alunos. A mediação didática Cartográfica proposta nesta pesquisa é, portanto, um subsídio nessa relação. A ideia central é por meio do desenvolvimento de atividades cartográficas previamente elaboradas promovendo a aprendizagem buscando a valorização dos conhecimentos adquiridos pelos alunos de EJA.

O processo desta pesquisa teve a Cartografia como mediadora do processo, pautando-se em uma coletânea de mapas e exercícios, no qual sua construção partiu do resgate de conhecimentos básicos de alfabetização cartográfica, já adquiridos pelos alunos, que se referem ao processo de domínio e aprendizagem de uma linguagem constituída de símbolos e significados; uma linguagem gráfica (códigos e símbolos definidos - convenções cartográficas), que permita aos mesmos organizarem uma sequência lógica de conceitos por meio da utilização de mapas. A utilização de mapas se justifica por possibilitarem um melhor aprendizado nas aulas de Geografia e por passarem informações visuais quase que de modo instantâneo.

O mapa, de acordo com Almeida e Passini (1989), é uma representação codificada de um determinado espaço real que pode ser chamado de um determinado modelo de comunicação, que se vale de sistema semiótico complexo (linguagem cartográfica) que se utiliza de três elementos básicos: sistema de signos, redução e projeção. Assim para se ler mapas é preciso saber qual o espaço representado, seus limites, suas informações.

A pesquisa pela mediação entre o conhecimento vivido do aluno e o conhecimento do professor da EJA pautou-se em uma coletânea de mapas e exercícios, partindo do resgate de conhecimentos básicos de alfabetização cartográfica já adquiridos pelos alunos. Estes já estavam inseridos na Terceira Etapa da EJA. Assim, foi organizada uma sequência lógica de conceitos geográficos fazen- 
do uso de mapas. Procuramos valorizar o conceito de lugar ampliando a escala de compreensão do espaço através de técnicas de representação, análise e comunicação de informações.

Fez parte, desta metodologia de trabalho o envolvimento dos professores de Geografia de EJA que já estavam inseridos na pesquisa, na tentativa de diversificar os recursos didáticos da coletânea para propiciar um efetivo processo de ensino-aprendizagem mediado pela Cartografia, contribuindo assim para a formação continuada deste profissional.

Por meio da mediação cartográfica, objetivou-se proporcionar aos professores de Geografia da EJA um modo de intervenção pedagógica de fato significativa para o desenvolvimento cognitivo dos alunos. A atividade foi planejada em conjunto com o professor de uma das turmas, uma vez que este havia concluído os conteúdos curriculares do bimestre. Assim, foi elaborada uma atividade que envolvesse tais conteúdos, na tentativa de viabilizar o processo de ensino-aprendizagem pelo mapa.

As atividades foram construídas conjuntamente com o professor, utilizando-se de seus saberes docentes e profissionais. Desta forma, procurou compor questões através da Cartografia que motivassem os alunos para realizar as seguintes cognições:

Interpretar as informações apresentadas nos mapas;

Possibilitar a construção dos principais conceitos geográficos em estudo.

Bueno (2008, p. 13) afirma que os conceitos geográficos são recursos intelectuais fundamentais para a compreensão dos diversos espaços e permita aos alunos e ao professor localizar e dar significados aos lugares e nessas significações e nas relações que estes têm com as experiências vividas individualmente (Quadro 2).

Quadro 2: conteúdo programático e conceitos geográficos Trabalhados na atividade

\begin{tabular}{|c|c|c|}
\hline $\begin{array}{c}\text { Conteúdo programático presente } \\
\text { nos Referenciais Curriculares- } 3^{\mathrm{a}} \\
\text { Etapa }\end{array}$ & Mapas utilizados & Conceitos geográficos \\
\hline \multirow{5}{*}{$\begin{array}{l}\text { Caracterização do espaço físico } \\
\text { do Estado de Goiás }\end{array}$} & Goiás-Relevo & \multirow{5}{*}{$\begin{array}{l}\text { Relevo } \\
\text { Cima } \\
\text { Hidrografia } \\
\text { Vegetação } \\
\text { Impacto Ambiental }\end{array}$} \\
\hline & Brasil - Climas & \\
\hline & Goiás - Bacias Hidrográficas & \\
\hline & Cerrado original & \\
\hline & Cerrado atual & \\
\hline
\end{tabular}

Organização: Rezende, 2014. Fonte: BUENO, 2008 
Nossa análise mostra que o uso da Cartografia na prática escolar, por meio do uso de mapas representou um recurso fundamental para a construção do processo de ensino-aprendizagem, capaz de unir o conhecimento dos indivíduos com os saberes sistematizados. As questões elaboradas motivaram os alunos à busca de informações nos mapas. Fator que influenciou a uma observação cuidadosa promovendo leitura e interpretação adequada dos dados.

Ao longo das questões procurou-se, sobretudo, destacar alguns conceitos geográficos e os conteúdos trabalhados adequadamente na Terceira Etapa de EJA, sempre considerando os conhecimentos prévios dos alunos, visando uma aprendizagem significativa par os mesmos.

Em conjunto com o professor da turma, foi indicado para a terceira atividade, um planejamento, pois o docente havia concluído os conteúdos curriculares do bimestre. Assim, foi elaborada uma atividade que envolveu tais conteúdos na tentativa de viabilizar o processo de ensino aprendizagem por meio da utilização do mapa. Os conceitos geográficos estão destacados e contidos nos mapas e nas questões a seguir.

\section{AS APROXIMAÇÕES ENTRE AS ANÁLISES E AS PROPOSTAS DA EJA}

As aproximações das análises e das propostas da EJA nos permitiu identificar quatro momentos distintos:

\section{Uma possível proposta da formação de professores da educação de jovens e adultos mediada pela Cartografia}

Por meio da pesquisa participante tentou-se estabelecer com o professor uma relação aberta de troca que acompanhou e proporcionou caminhos durante o processo da pesquisa através de diálogos, entrevistas, questionários, telefonemas e e-mail. Questionamos o professor de Geografia de EJA sobre sua prática docente e propusemos juntamente com o mesmo, uma metodologia que viesse a contribuir para o processo de ensino-aprendizagem de Geografia, mediado pela Cartografia. Foi elaborada uma coletânea de mapas e exercícios, com o intuito de realizarmos uma "ponte" entre conteúdo, mapa e o cotidiano do aluno.

Antes de realizarmos a aula de alfabetização cartográfica notamos que nas atividades aplicadas que continham mapas utilizados pelo professor, os alunos mostravam dificuldades na leitura e interpretação dos mapas. Eles mostraram dificuldades quanto à leitura da legenda, uma vez que o professor partia do pressuposto de que, por se tratar de alunos da Terceira Etapa da EJA estes já estariam alfabetizados cartograficamente.

Após procedermos à aula específica com noções de alfabetização cartográfica verificamos uma melhora na leitura e interpretação dos mapas pelos alunos, visto que, o mapa é um importante transmissor de informações.

Simielli (2011) expõe com solidez essa afirmação:

Ao pensar o mapa como transmissor de informações, deve-se ter em mente os princípios da comunicação em cartografia. Se os mapas são veículos no processo de comunicação, mediante símbolos 
cartográficos, é preciso apresentar a informação adequadamente e, para tanto, conhecer as regras da comunicação e assim expressar como dizer o que?, como?, e para quem?.

Para se entender plenamente a linguagem cartográfica, é preciso destacar aqui a importância da semiótica, ciência geral de todas as linguagens, mais especialmente dos signos. O signo é algo que representa o seu próprio objeto. Ele só é signo se tiver o poder de representar esse objeto, colocar-se no lugar dele, e então, ele só pode representar esse objetivo de um certo modo e com uma certa capacidade. O signo só pode representar seu objeto para um intérprete, produzindo na mente deste um outro signo, considerado o fato de que o significado de um signo é outro signo. (Simielli, 2011, p. 78)

Diante disso, refletimos sobre quais seriam as habilidades que os alunos de EJA deveriam possuir para que os mesmos entendessem os signos apresentados nos mapas. Para compreender como ocorre a relação dos signos com o objeto real, recorremos então às noções de semiologia gráfica abordada por Simielli (2007), onde o signo representa um objeto e que aquele só pode representar tal objeto no instante em que o leitor produz em sua mente outro signo, portanto o significado de um signo é outro signo. A autora nos elucida ainda que o signo é desmembrado em duas partes: o significante e o significado. O significante seria o a parte material ou concreta do signo, sendo audível o/ou legível. Nesse contexto, ao significado cabe a parte imaterial, conceitual do signo, assim, o significante seria a expressão, o desenho e a legenda desse desenho. A interpretação mental e o produto final dessa interpretação - entre significante e significado - é a significação, e o processo para se chegar a tal significação recebe então o nome de decodificação.

Torna-se importante para a análise destas atividades a compreensão do processo de decodificação dos mapas pelos alunos de EJA. Nesse sentido, ao compor as atividades cartográficas presentes nesta pesquisa, foi percebido que os mapas selecionados a partir da Geografia de Goiás não poderiam ser apenas apresentados aos alunos da EJA, sendo necessário realizar uma retomada da alfabetização cartográfica para esclarecer aos alunos a respeito do significado dos símbolos apresentados por esses mapas, para que os estudantes pudessem realizar o processo de decodificação sem maiores dificuldades.

Cabe aqui destacar a indispensável ação do professor no processo de decodificação dos mapas pelos estudantes, pois é a partir do apoio do professor que os alunos poderão decodificá-los de maneira mais adequada.

De acordo com Simielli (2007) se o professor dominar a linguagem gráfica e souber transmiti-la aos seus alunos, o problema de dificuldades na leitura e interpretação de mapas poderá ser aos poucos solucionado, uma vez que o aluno, segundo a autora, precisa conhecer e se familiarizar com o alfabeto cartográfico e isso é tarefa do professor (SIMIELLI, 2007, p. 84).

Risette e Castellar (2011, p. 641) defendem a importância do aprendizado dos alunos a lerem e interpretarem mapas, assim como o papel indispensável do professor como mediador do processo da aprendizagem da linguagem cartográfica:

Aprender a ler um mapa significa ampliar o nosso conhecimento da realidade que nos é apresentada, significa termos a possibilidade de compararmos as informações contidas no mapa com a realidade e criticarmos positiva ou negativamente as concepções adotadas pelo profissional que o elaborou, além disso, significa aprender uma nova forma de comunicação, uma nova forma de produzir e interpretar informações, significa, enfim, o letramento geográfico. 
Para o "letramento geográfico" é imprescindível o desempenho do professor como mediador do processo de aprendizagem da linguagem cartográfica e a importância desta aprendizagem para o desenvolvimento cognitivo e melhora na compreensão do espaço pelos estudantes.

Nessa perspectiva, o preparo dos professores do Ensino Fundamental e Médio para que estes estejam aptos a ensinar a linguagem cartográfica esbarra na formação básica dos professores e, principalmente, nos programas de formação continuada.

Diante disso, Bueno (2008) defende a necessidade de o meio acadêmico reconhecer a Cartografia Escolar como disciplina acadêmica, tanto nos cursos de Licenciatura em Geografia, quanto nos cursos de Pedagogia. Tal reconhecimento auxiliaria na formação dos professores de Geografia, inclusive de EJA.

A autora complementa dizendo que, devido às mudanças ocorridas na LDB/96, tem sido possível a realização de algumas alterações nas matrizes curriculares dos cursos de formação de professores. A efetivação da disciplina de Cartografia Escolar proporcionaria uma melhoria nas aulas de Geografia, uma vez que pesquisas tem mostrado que muitos professores evitam trabalhar com mapas devido a dificuldades ou falta de habilidade com a Cartografia. Assim, as alterações nas matrizes curriculares dos cursos de formação de professores podem vir a ser de grande valia para o preparo destes profissionais, no que tange ao processo de ensino da linguagem cartográfica aos seus alunos.

Nesta pesquisa os resultados das atividades realizadas possibilitaram uma mudança do olhar do professor, uma vez que, como relatado anteriormente, pode-se perceber que os alunos mostraram dificuldades na realização e interpretação das atividades que continham mapas aplicados pelo professor anteriormente a aula de alfabetização cartográfica e que após a aula ministrada especificamente com as noções de alfabetização cartográfica (leia-se, nossa intervenção) os alunos demonstraram uma maior facilidade na leitura e interpretação das mesmas.

Por meio das atividades com mapas que traziam como foco o estudo do lugar, que no caso dessa pesquisa foi utilizada a representação cartográfica dos conteúdos relacionados a Geografia de Goiás, os alunos da EJA demonstraram uma melhora no processo de ensino-aprendizagem que foi mediado pela Cartografia. Podemos destacar que conhecer como os alunos de EJA percebem e interpretam o espaço pode auxiliar muito o trabalho docente, especialmente na preparação de atividades de ensino que contribuem para a aquisição gradativa de diferentes modos de representação espacial, cada vez mais próximos da vivência dos alunos jovens e adultos.

\section{Relação entre conteúdo, mapa e o cotidiano do aluno}

A relação entre conteúdo, mapa e o cotidiano do aluno pôde ser observada durante a terceira atividade (da coletânea de mapas e exercícios) quando pedimos aos alunos que localizassem pontos específicos nos mapas e relacionassem os nomes desses pontos. Todos realizaram com sucesso e vários ainda acrescentaram outros pontos de seus conhecimentos que não estavam especificados nos mapas mostrando os conhecimentos adquiridos ao longo de suas vidas.

Durante as aulas, ao lerem o mapa do Relevo do Estado de Goiás (Figura 01) os alunos expressaram conhecer serras, planaltos, rios e depressões que estavam relacionadas no mapa, o que acabou 
promovendo um diálogo entre os estudantes e o professor. Pudemos então perceber que este diálogo proporcionou motivação e possibilitou uma melhora no processo de ensino-aprendizagem.

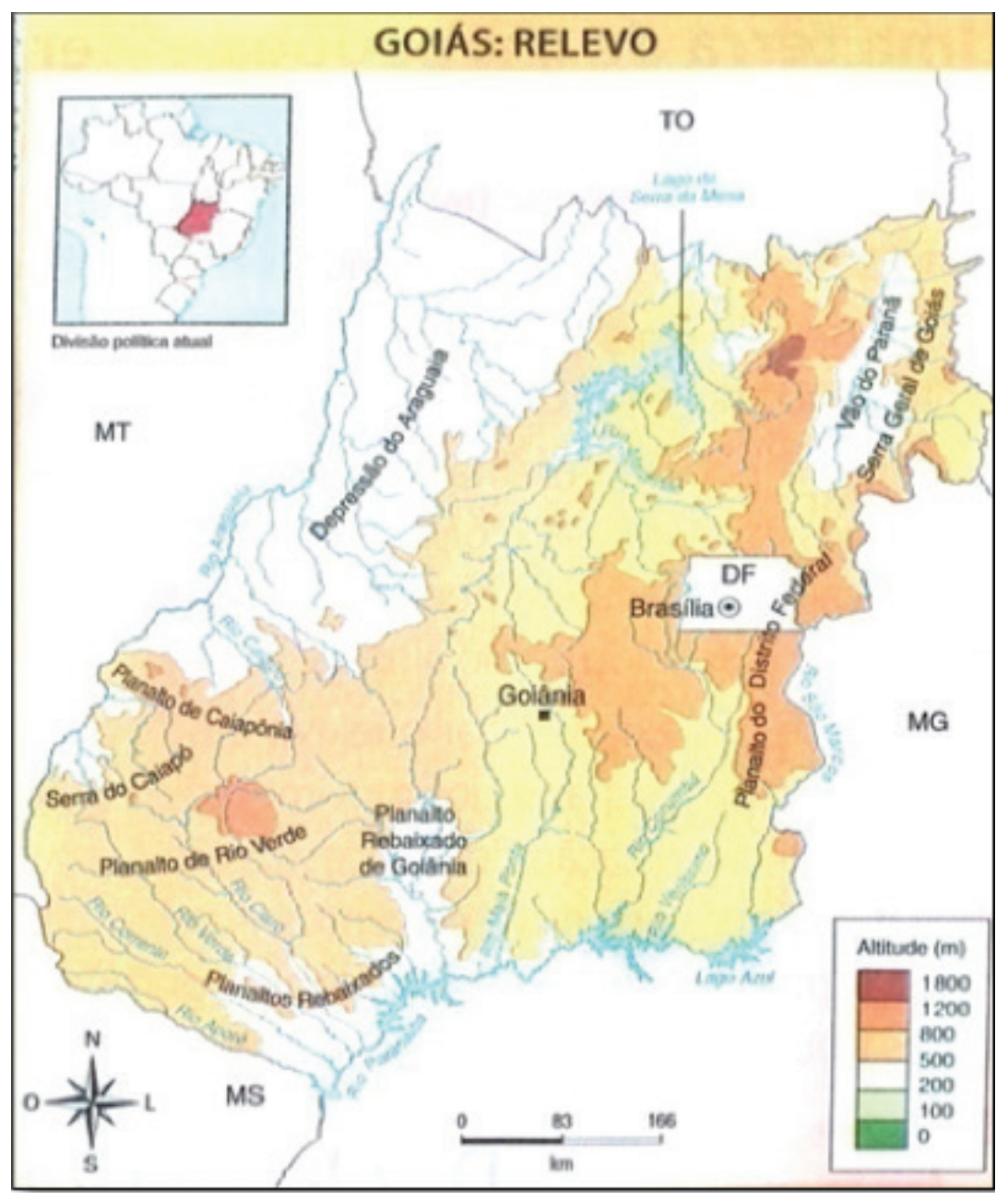

Figura 01 - Mapa de Goiás: Relevo

Fonte: Adaptado do Atlas geográfico escolar. IBGE, 2007.

Os olhares dos alunos de EJA aos mapas do Estado de Goiás nos mostraram que a mediação cartográfica com a utilização de mapas do Estado ao qual residem, se utilizada pelos professores, pode abrir uma possibilidade de o mapa deixar de ser algo, aparentemente, frio e impessoal, distante da realidade vivida dos alunos, mostrando assim a importância dos mapas na vida cotidiana desses sujeitos.

Nesta pesquisa, os alunos indicaram nos mapas utilizados nas aulas locais conhecidos ou que os mesmos gostariam de conhecer. Assim, como afirma Seemann (2013), o mapa pode se tornar como um livro conhecido, onde o leitor seja capaz de lê-lo como um texto cheio de significado, pois nele podem conter os olhos destes alunos que trazem uma história de vida e informações pessoais. Para Seemann (2013, p. 102), o mapa possui os seguintes significados: 
O mapa é como um livro conhecido ou um álbum de família, e o leitor é capaz de ler o mapa como um texto com um significado, porque ele traz ao olho da mente paisagens, eventos e pessoas do próprio passado, envolvendo a própria identidade na representação, ou em outras palavras, os mapas são uma rica fonte histórica pessoal, e eles dão um conjunto de coordenadas para o mapa da nossa memória.

Este autor nos apresenta ainda uma interpretação do mapa do espaço vivido como uma biografia, algo que se enquadra bem quando trabalhado em salas de aula da EJA. Esta biografia pode ser definida em quatro sentidos (Quadro 3).

Quadro 3 - os quatro sentidos do mapa conforme seemann (2013)

\begin{tabular}{|l|l|l|l|}
\hline \multicolumn{1}{|c|}{ I SENTIDO } & \multicolumn{1}{c|}{ II SENTIDO } & \multicolumn{1}{c|}{ III SENTIDO } & \multicolumn{1}{c|}{ IV SENTIDO } \\
\hline $\begin{array}{l}\text { O mapa no papel } \\
\text { possuir uma biografia } \\
\text { própria, uma vez que } \\
\text { se trata de um material } \\
\text { concreto planejado, } \\
\text { realizado e utilizado em } \\
\text { determinado espaço e } \\
\text { tempo específico. }\end{array}$ & $\begin{array}{l}\text { Possibilidade de o } \\
\text { mapa estabelecer uma } \\
\text { identificação entre seus } \\
\text { realizadores e de outras } \\
\text { pessoas que tenham } \\
\text { acesso ao mesmo } \\
\text { material. }\end{array}$ & $\begin{array}{l}\text { Eloquência em retratar } \\
\text { a paisagem talvez } \\
\text { de uma forma mais } \\
\text { objetiva do que muitas } \\
\text { palavras ou textos }\end{array}$ & $\begin{array}{l}\text { Se dá como uma } \\
\text { biografia, devido à } \\
\text { possibilidade de este } \\
\text { ir de encontro às } \\
\text { referências vividas, as } \\
\text { práticas sociais das } \\
\text { pessoas estimulando suas } \\
\text { memórias e promovendo } \\
\text { uma aprendizagem } \\
\text { significativa }\end{array}$ \\
\hline
\end{tabular}

Organização: Rezende, 2014. Fonte: Seemann, 2013

Outro fator importante que pode contribuir com o processo de ensino-aprendizagem são as experiências vividas pelos professores e alunos no(s) lugar(es), podendo assim ampliar o ensino. Este contexto se mostrou bastante evidente ao longo desta pesquisa, pois estes sujeitos demonstraram tanto em diálogos como nas atividades propostas uma identificação do mapa com a percepção de significados, como informações pessoais de locais em que moram, que conhecem ou que sabiam por meio do relato de seus parentes.

Diante disso, entendemos que os professores da EJA precisam fazer o uso dos saberes dos alunos, esta é uma questão fundamental para a reflexão das práticas escolares dos docentes. Pelo exposto, Almeida (2009, p. 09) nos assegura que:

Os conhecimentos da geografia local permitem a inclusão de saberes elaborados fora da escola, por todos que vivem no lugar e por aqueles que já viveram em diferentes lugares (migrantes). Esses saberes passam a concorrer com aqueles apresentados nos materiais escolares, criando uma demanda por novas práticas docentes com o apoio de materiais escolares específicos sobre o lugar. A necessidade de mapas escolares locais vem fomentando então a produção de mapas e atlas que abordem o lugar. 
A possibilidade de discutir a Cartografia a partir do estudo do lugar, preparando o aluno e o professor para entenderem mapas é ressaltada por Bueno (2008, p. 129):

A cada dia mais percebe-se a necessidade de saber "pensar" o lugar. Dentro de uma proposta socioconstrutivista, trabalhar com o lugar e suas representações faz com que o aluno e o professor se percebam mais integrados ao processo de construção do conhecimento.

Para a autora, os conceitos geográficos são instrumentos básicos para a leitura do mundo do ponto de vista geográfico, "são recursos intelectuais fundamentais para a compreensão dos diversos espaços [...] que permitem ao aluno e ao professor, localizar e dar significações aos lugares". Daí a importância do lugar, sua significação e a sua relação com a história de cada indivíduo.

\section{O mapa como representação espacial da informação em diferentes tempos}

Para que os alunos da EJA pudessem analisar mapas como representação espacial da informação em diferentes tempos, apresentamos aos mesmos dois mapas com intuito de comparação. O primeiro sobrepujava informações sobre a extensão do Bioma Cerrado original, já o segundo demonstrava a extensão atual do Bioma Cerrado (Figura 02).

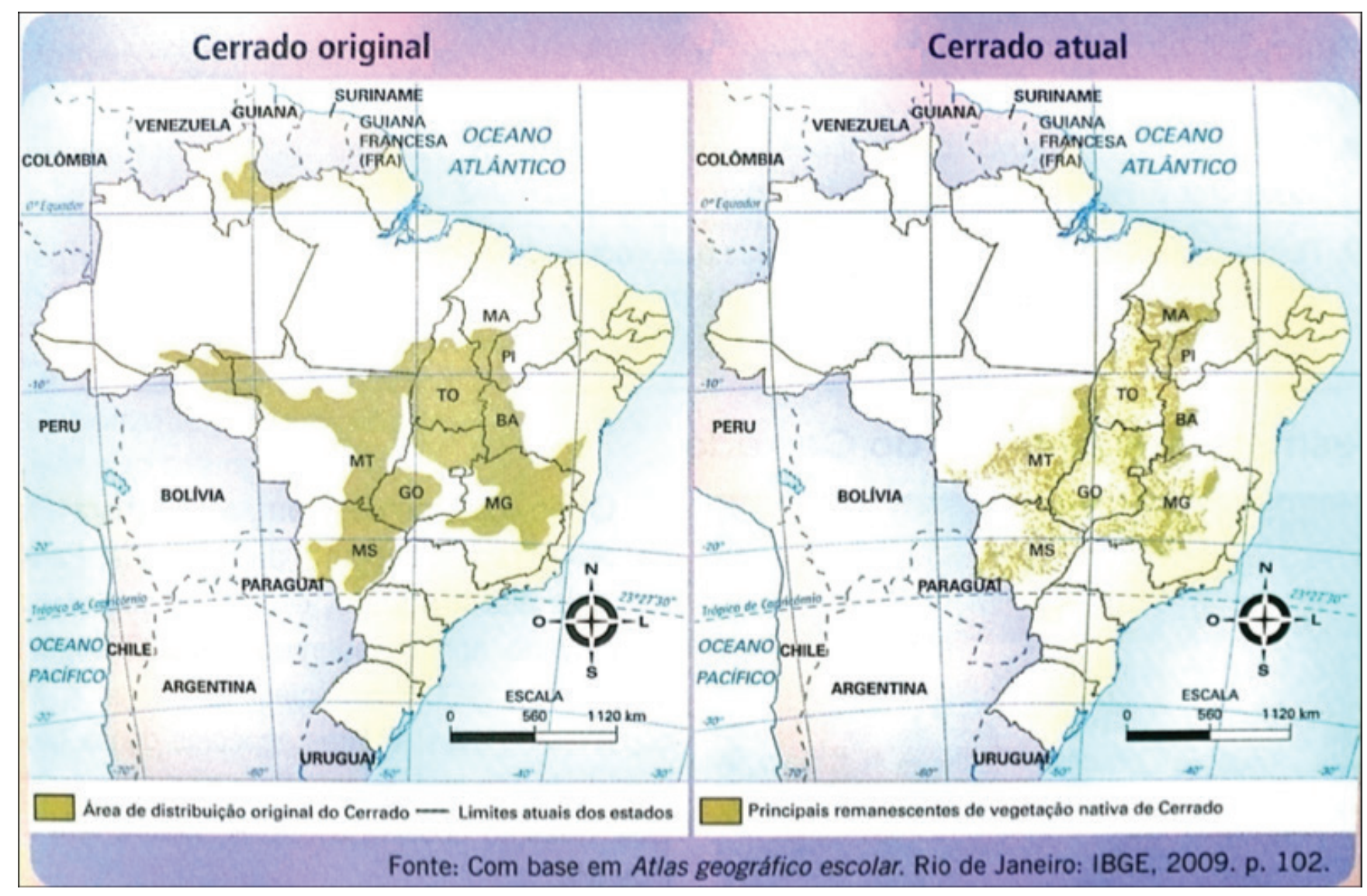

Figura 02 - Mapas do Brasil: Cerrado original e atual

Fonte: IBGE, 2009 
Após a leitura desse mapa foi solicitado aos alunos que discorressem sobre suas conclusões. Vale destacar que esperávamos que os alunos fossem capazes de realizar a leitura e a interpretação dos mapas e que em seus comentários transparecessem os conhecimentos adquiridos por estes alunos. Assim selecionamos algumas respostas:

Quadro 4 - análises dos alunos sobre a representação espacial da informação em diferentes tempos

"Comparando as informações contidas nos mapas, percebe-se o quanto o Bioma Cerrado foi desmatado e que resta pouco em vista do que havia de Cerrado no Brasil".

"Conclusão, antes o Cerrado tinha muitas arvores típicas, hoje com a plantação de soja, milho, cana de açúcar e agropecuária estão bem diferentes."

"Pode-se concluir que no Cerrado Original (mapa) havia mais vegetação nativa do Cerrado, diferente do Cerrado Atual que teve sua vegetação substituída por agroindústrias."

"Que hoje está bem desmatado, ao longo do tempo se continuar desta forma o Cerrado vai se extinguir."

"Compara-se aos governantes que se preocupam muito pouco com o meio ambiente."

Organização: Rezende, 2014.

Os alunos não só conseguiram realizar a comparação dos mapas do Bioma Cerrado com sucesso como também em seus comentários deixaram evidente seus conhecimentos a respeito dos impactos ambientais, da influência das atividades econômicas sobre este desmatamento e a responsabilidade dos governantes sobre tal questão.

Respaldamo-nos em Lesann (2009, p. 197) para demonstrarmos a relevância de se trabalhar com diversos mapas em sala de aula, através de comparações entre si, para que se entendam as diferenças e semelhanças, ordens e grandezas de fatos e fenômenos geográficos relacionados a um mesmo espaço em escalas diferentes.

O objetivo de se trabalhar com mapas diferentes que mostram um mesmo fenômeno em diferentes épocas possibilita a compreensão de variações de um determinado tema, no tempo. Assim, as análises de diversos mapas enriquecem intensamente a análise e interpretações de fatos e fenômenos observados sob diferentes olhares, possibilitando a formação de raciocínios mais complexos e rápidos.

A coletânea de mapas mostrou como a transformação do espaço é temporal. Essa aprendizagem vai ao encontro às habilidades esperadas na construção do conhecimento, pois ao visualizar os mapas torna-se mais compreensível o entendimento dos fenômenos e/ou conteúdos geográficos.

\section{CONSIDERAÇÕES FINAIS}

Ao analisarmos o papel da Geografia Escolar e da Cartografia no processo de ensino-aprendiza- 
gem dos alunos da EJA e na formação continuada do professor dessa modalidade de ensino, temos condições de observar a potencialidade de propostas pedagógicas que reconhecem as características específicas dos sujeitos envolvidos nesse contexto. Acreditamos que a construção do conhecimento geográfico e cartográfico pode contribuir nos desafios presentes no trabalho da EJA, por possibilitar recursos aos estudantes para compreender e interpretar a realidade. Apresentamos, também, uma proposta de aproximação entre os conhecimentos científicos e os conhecimentos já adquiridos pelos alunos em sua vida cotidiana, através de uma mediação cartográfica planejada juntamente com o professor de Geografia da EJA, afim de evidenciar nossos objetivos.

Em nossa pesquisa constatamos que a mediação cartográfica proporciona ao professor de Geografia da EJA um modo de intervenção pedagógica significativa para o desenvolvimento intelectual dos alunos. As análises dos resultados mostraram que a alfabetização cartográfica permite a assimilação de conceitos e possibilita aos alunos se sentirem mais a vontade diante de mapas que trazem informações locais a respeito do Estado em que reside, além de enfatizar a Cartografia como parte da vida cotidiana. Ressaltamos, então, a importância de os professores de EJA por meio de uma educação contextualizada e significativa desenvolverem o processo de ensino-aprendizagem partindo do conhecimento prévio dos estudantes. Enfim, estabelecendo como ponto de partida aquilo que os alunos trazem consigo de suas histórias de vida e das experiências cotidianas. O professor poderá desenvolver saberes que possam valer para o mundo das relações, o conviver, o ser e o fazer.

Destacamos o papel indispensável do professor como mediador do processo de aprendizagem da linguagem cartográfica e a importância desta aprendizagem para o desenvolvimento cognitivo e a melhora na compreensão do espaço pelos estudantes de EJA. O preparo dos professores do Ensino Fundamental e Médio para estarem aptos a ensinar a linguagem cartográfica esbarra constantemente na formação básica dos professores e, principalmente nos programas de formação continuada. A metodologia apresentada nesta pesquisa mostra um dos caminhos que apontam para uma contribuição quanto a formação continuada de professores da EJA.

Por fim, ressaltamos que os docentes dessa modalidade de ensino precisam buscar os conhecimentos prévios dos alunos e, partindo deles, aprofundá-los para auxiliar aos estudantes a estabelecerem relações, comparações, interpretações e ampliações suas noções espaciais a partir de suas experiências cotidianas. Com base nesse estudo reafirmamos a importância de possibilitar que a formação dos saberes geográficos faça parte das atividades escolares dos alunos da EJA, como processo de construção de uma cidadania.

\section{REFERÊNCIAS}

Almeida, R. D.; Passini, E. Y. O espaço geográfico: ensino e representação. 1. Ed. São Paulo: Contexto, 1989.

Almeida, Rosangela Doin. Do desenho do mapa: iniciação cartográfica na escola. São Paulo: Contexto, 2001.

Almeida. Rosângela Doin. Cartografia e infância. VI Colóquio de Cartografia para Crianças e II Fórum Latino-americano de Cartografia para Escolares. Universidade Federal de Juiz de Fora. MG 2009. 
Antunes, Celso. Geografia para a Educação de Jovens e Adultos. Petrópolis, RJ: Vozes, 2012.

Brasil. Lei de Diretrizes e Bases da Educação Nacional. Lei no 9394, de 20 de dezembro de 1996. Estabelece as diretrizes e bases da educação nacional. Brasília, DF, 1996.

. Resolução $n^{\circ} 1$, de 5 de julho de 2000. Estabelece as diretrizes curriculares nacionais para a educação de jovens e adultos. Diário Oficial da União, Brasília, 19. jul. 2000b. Disponível em: <portal. mec.gov.br/cne/arquivos/pdf/CEB012000.pdf>.

. Lei $n^{\circ}$ 9.394, de 20 de dezembro de 1996. Estabelece as diretrizes e bases da educação nacional. Diário Oficial da União, Brasília, 23 dez. 1996a. Disponível em: <http://www.planalto.gov.br/ ccivil_03/LEIS/19394.htm>.

. MEC. Lei de Diretrizes e Bases da Educação. Disponível em: <http://www.mec.gov.br>. Acesso em: 25 ago. 2013.

. MEC. Lei de Diretrizes e Base da Educação no 5692 de 11.08.71, capitulo IV. Ensino Supletivo. Legislação do Ensino Supletivo, MEC, DFU, Departamento de Documentação e Divulgação, Brasília, 1974.

. MEC. Lei no 9.394/96 - Diretrizes e Bases da Educação Nacional. Brasília - DF: Congresso Nacional. 23 de dezembro de 1996.

. MEC. Parecer CEB 11/2000. In: SOARES, Leôncio. Diretrizes Curriculares Nacionais: Educação de Jovens e Adultos. Rio de Janeiro: DP\&A, 2002.

. MEC. Resolução CNE/CEB 1/2000. In: SOARES, Leôncio. Diretrizes Curriculares Nacionais: Educação de Jovens e Adultos. Rio de Janeiro: DP\&A, 2002.

Bueno, Míriam Aparecida. Atlas escolares municipais e a possibilidade de formação continuada de professores: um estudo de caso em Sena Madureira/AC. Tese (doutorado) Universidade Estadual de Campinas, Instituto de Geociências. SP. 2008.

Cavalcanti, Lana de Souza. Geografia e prática de ensino. Goiânia: Alternativa, 2002.

Encontro Nacional De Educação De Jovens E Adultos (ENEJA), 9., 2007, Faxinal do Céu/PR. Relatório-síntese. Disponível em: <http://www.forumeja. org.br>. Acesso em: 28 set. 2013.

Goiás. Secretaria de Estado da Educação - Coordenação de Educação a Distancia. Diretrizes da Educação de Jovens e Adultos do Estado de Goiás. Goiânia: SEDUC, 2010.

. Secretaria de Estado da Educação - Conselho Estadual de Educação do Estado de Goiás Resolução do $\mathrm{n}^{\circ} 260$, de 18 de novembro de 2005.

Le Sann, Janine G. Metodologia para introdução a Geografia no ensino fundamental. In: Almeida. Rosângela Doin (org.). Cartografia Escolar. Ed. Contexto. São Paulo. 2011. 
Lima, Sélvia Carneiro de; Junqueira, Silas Martin; Rigonato,Valney Dias. Projetos regionais: Goiás: Geografia, $4^{\circ} / 5^{\circ}$ ano: Ensino Fundamental. Ed. Esfera. 2011.

Machado, Maria Margarida. A politica de formação de professores que atuam na educação de jovens e adultos em Goiás na década de 1990. Tese (doutorado) Programa de Estudos Pós-Graduados em Educação: História, Política, Sociedade. Pontifícia Universidade Católica de São Paulo. SP. 2001.

. Formação de professores para EJA: Uma perspectiva de mudança. In: Revista Retratos da Escola, Brasília, v. 2, n. 2-3, p. 161-174, jan./dez. 2008. Disponível em: <http//www.esforce. org.br>

Machado, M. M. \& Silva, D. C. da. O contexto da Educação de Jovens e Adultos no Estado de Goiás. In: MACHADO, M. M (org.). Percursos Históricos da Educação no Cerrado. Campinas, SP: Mercado das Letras, 2012.

Oliveira, Ivanilton José de; Arrais, Tadeu Alencar. Geografia de Goiás, $4^{\circ}$ ano ou $5^{\circ}$ ano: Ensino Fundamental. São Paulo: Scipione. 2008.

Resende, Márcia Spyer. A geografia do aluno trabalhador. São Paulo, Loyola: 1986.

Ribeiro, Reuvia de Oliveira. Formação cidadã, juventude e trabalho: a Geografia na Educação de Jovens e Adultos (EJA). Dissertação de Mestrado Programa de Pesquisa e Pós-Graduação em Geografia do Instituto de Estudos Sócio-Ambientais da Universidade Federal de Goiás- UFG/ Goiânia, GO. 2011.

Risette, Márcia Cristina Urze. Castellar, Sônia Maria Vanzella. O estudo do bairro por meio das representações cartográficas: uma proposta de sequência didática para estudantes dos sétimos e oitavos anos da rede estadual paulista - Zona Leste da capital. In: Anais do VII Colóquio de Cartografia para Crianças e Escolares. Vitória, 2011.

Romão, J.E. Educação de jovens e adultos: o desafio do final do século. São Paulo: IPF, 1999. 36p. (Série "Cadernos de EJA", n. 5).

Seemann, Jorn. Cartografia-crônicas: uma viagem pelo mundo da Cartografia. Fortaleza: Expressão Gráfica e Editora, 2013.

Simielli, Maria Elena Ramos. A Geografia na Sala de Aula: Cartografia no Ensino Fundamental e Médio. 5 ed. São Paulo: Contexto, 2003.

. O mapa como meio de comunicação e alfabetização cartográfica. In: Almeida, R. D. (org.). Cartografia Escolar. $2^{a}$ ed. São Paulo: Contexto, 2011.

UNESCO. IV Conferência Internacional sobre Educação de Adultos. Marco de ação de Belém, Brasil, abril de 2010. 